\title{
Infusing Creativity into Technology Education Through an Understanding of Neuroscience
}

\author{
Scott Bartholomew (corresponding author) \\ Technology \& Engineering Education, Utah State University \\ 79 W 400 S, Logan, Utah 84321, United States
}

Tel: 1-801-368-7875 E-mail: scott.bartholomew@aggiemail.usu.edu

Received: November 22, 2013 Accepted: December 20, 2013 Published: December 31, 2013

doi:10.5296/jet.vli1.4859 URL: http://dx.doi.org/10.5296/jet.v1i1.4859

\begin{abstract}
This paper explores possibilities for infusing technology education with neuroscience principles in an effort to increase creativity. The decline in creativity among individuals in the United States is highlighted. Basic neuroscience fundamentals are covered and a framework for describing creativity in individuals is provided (Dietrich, 2004). Pedagogical connections and suggestions are provided for implementing neuroscience concepts in the classroom in an effort to promote creativity.
\end{abstract}

Keywords: technology education, creativity, neuroscience

\section{Creativity Findings}

A recent IBM poll of 1,500 CEOs identified creativity as the No. 1 "leadership competency" of the future (IBM, 2010). Creativity is specifically mentioned in the Standards for Technological Literacy (ITEA, 2007) as a component of five different standards (1, 2, 8, 9, 10). Despite the high status of creativity, the creativity scores of children have steadily decreased since 1990 (Kim, 2011). The author of that study analyzed almost 300,000 Torrance Creativity scores of children and concluded that the major decrease is seen in the scores of younger children in America - from kindergarten through sixth grade. Adobe (2012) found similar problems with creativity in society; in the study State of Create: global benchmark study, Adobe reports that $82 \%$ of Americans do not believe they are living up to their creative potential, and $70 \%$ of Americans suggest that creativity is being stifled by our educational system. Technology education is uniquely situated to help reverse the creativity problems addressed in current research. Creative tools and technology were perceived as some of the largest impact factors for "overcom[ing] creative limitations," "provid[ing] inspiration," and "increas[ing] creativity." (Adobe, 2012, p. 2) 
Recent research on creativity in the fields of neuroscience reveals the amazing complexity of the creative processes in the brain (Dietrich, 2004; Dietrich, 2007; Dubinsky, 2013; Srinivasan, 2007; Ward, 2004). Several studies have been conducted to describe the relationship between knowledge-level and creative capacity (Dietrich, 2004; Fink, 2007) as well as skill level and creative capacity (Christiaans \& Venselaar, 2005). Despite the significant scientific advances in creativity, neuroscience, and brain research, the field of neuroscience has had little impact on educational practices (Clement \& Lovat, 2012; Dubinsky, 2013). With the potential for substantial impact on classroom practices K-12 technology education, the field is strikingly devoid of neuroscience principle integration.

\section{Prefrontal Cortex}

A basic understanding of neuroscience and human brain functions begins with the prefrontal cortex. The prefrontal cortex (located at the front of the brain, below the area of the forehead) has been identified as the central structure involved in creative thinking (Dietrich, 2004; Dubinsky, 2013; Srinivasan, 2007). While other areas in the brain control long-term memory, fact processing, and other cognitive functions, the prefrontal cortex manages executive functions - taking highly processed information and making decisions. Decisions and behaviors based on prefrontal cortex processes are the most sophisticated. In addition to high-level cognitive processes, the prefrontal cortex performs three key functions related to creativity: working memory (Dietrich, 2004; Fuster, 2000), temporal integration (Dietrich, 2004; Fuster, 1995), and sustained directed attention (Dietrich, 2004; Sarter, Givens, \& Bruno, 2001). Working memory is our ability to process information real-time; working memory keeps relevant information temporally stored so it is readily accessible if needed and has been tied to cognitive flexibility, abstract thinking, and creative thinking (Dietrich, 2004). Cowan (2001) found that $4 \pm 1$ represents the total number of items that can be held in working memory at a single moment in time (see also Miller's Law in Miller, 1956). This finding holds true only if the "chunks" of information are logically consistent (sequence of numbers, related words, etc.). The number of informational chunks capable of being retained recedes quickly for any random or unrelated piece of information.

Temporal integration, a second function of the prefrontal cortex, allows for the temporary integration of previously separate ideas. Learned concepts and ideas can be temporarily brought forward and represented for situational needs and applications. Finally, the third key prefrontal cortex function, sustained directed attention, relates to creativity in problem-solving situations. Dietrich (2004) states: "the ability to deliberately direct attention to pertinent information must be a prerequisite for creative thinking that is a result of effortful, constructive problem solving." Creatively solving problems is made possible, in part, by the ability to sustain directed attention to the task at hand.

\section{Neuroscience Concepts}

While this study surveyed many existing definitions of creativity, recently a commonly used definition has developed involving concepts that are considered both "novel" and "useful" (Fink, 2007; Ward, 2004). The broad classification of these creative ideas and their generation has led to considerable debate and an extensive range of theories and various models of creativity have been 
proposed (Dietrich, 2004, Fink, 2007, Srinivasan, 2007). Dietrich (2004), a renowned author in neuroscience, proposed a taxonomy consisting of four types of creative insights: deliberate-cognitive, deliberate-emotional, spontaneous-cognitive, and spontaneous-emotional.

\section{Deliberate-Cognitive}

Deliberate-cognitive mode creativity refers to creativity manifested while consciously focusing on a task or problem at hand. This form of creativity relies mainly on expertise in a given area. The quantity of domain-specific informational items stored is directly responsible for the deliberate-cognitive creativity level of an individual. More domain-specific items that can be accessed by the prefrontal cortex allow an individual more "tools" to use when solving a problem. Expertise alone does not translate into creativity, a "nimble" or "productive" prefrontal cortex is also a requisite for this type of creativity - you must be able to draw from, synthesize, understand, and assess the various informational items related to a specific domain. Thomas Edison's work on the light bulb is an example of deliberate-cognitive creativity: intense focus on the task combined with cognitive knowledge and understanding in the creation of the light bulb.

\section{Deliberate-Emotional}

In deliberate-emotional creativity, the individual does not rely upon domain-specific knowledge in order to demonstrate creativity; rather, the individual focuses brain resources toward retrieving affective memories stored in emotionally charged ways. Musicians, artists, and performers often demonstrate deliberate-emotional creativity. The actual notes in a popular music piece may not require extensive understanding of music theory to understand, however, the ability to infuse a few simple chords in an emotionally-moving experience is a skill not routinely possessed by all individuals. Few would argue that The Beatles were not creative just because their music requires little formal musical knowledge to play. Modern jazz music is often performed by performers who chose from a few chords and manipulate them in an entertaining and emotionally charged way. This type of creative insight is usually restricted to those with an "endowed" prefrontal cortex, a natural disposition towards these types of creative acts. Society values the creativity of individuals who can infuse their own emotions into a particular venue in a unique way.

\section{Spontaneous-Cognitive}

Spontaneous-cognitive creative experiences are often described as the "light-bulb" moments or "being hit by a ton of bricks." These creative experiences most often occur during a relaxed state of mental activity. Previously unrelated chunks of information are allowed to move freely in and out of the working memory. Unforeseen connections, solutions, and previously "hidden" details often emerge from this type of exercise. In fact, some of the most notable discoveries in science are of this type: Newton thinking of gravity while watching an apple fall (Hamblyn, 2011) and Einstein conjecturing about relativity while imagining himself riding on a beam of light (Norton, 2013). A high level of domain-specific knowledge is required for this type of creativity in order to produce quality creative moments. The more relevant chunks of information that exist, the greater the likelihood a spontaneous connection will be made during a relaxed mental state. 


\section{Spontaneous-Emotional}

Spontaneous-emotional creativity is often referred to as an "epiphany." Emotional memories and feelings can combine with other chunks of information during moments of relaxed mental activity to form epiphany-type moments of insight. Emotional-spontaneous insights are not domain-specific and usually take the form of "universal truths" impressed upon the individual. Artistic expressions, poems, and emotionally charged pieces are often the result of spontaneous-emotional creativity. George Frederic Handel's Messiah could be representative of this category. In 1741, Handel composed the massive 259-page Baroque-style oratorio in just 24 days. This experience was marked with deep emotional connection to the music and creative genius in a way that typifies spontaneous-emotional creativity.

\section{Knowledge and Creativity}

The divide that separates different theories regarding knowledge level and creativity is significant with scholars proposing that knowledge is a prerequisite of creativity; conversely, other scholars argue that knowledge is an inhibitor to creativity (Ward, 2004). An implementation of Dietrich's (2004) proposed creativity classifications allows both parties to describe different manifestations of creativity. For example, cognitive expressions of creative insight rely on domain-specific knowledge, while emotional forms of creativity depend on emotions and do not necessitate domain-specific knowledge. The exhibition of creativity in highly cognitive fields (science and mathematics) usually occurs among adults, after enough formal knowledge has been acquired to allow for deliberate-cognitive and spontaneous-cognitive functions to occur (Dietrich, 2004). Conversely, creativity in deliberate-emotional and spontaneous-emotional fields (music and art) can be exhibited at a much younger age, with much less knowledge (Dietrich, 2004).

\section{Plasticity}

In 2008 The Society for Neuroscience published The Neuroscience Core Concepts, a table that sets forth "big ideas" in the field of Neuroscience. A significant idea set forth in this table is the concept of plasticity, implying that synaptic-level connections among neurons are plastic, and these connections change with practical experiences. The strength in the relationship between these neurons is dynamic, becoming stronger or weaker with use or inactivity. Learning and practicing skills strengthens these connections while inactivity weakens the connection. A synaptic-level connection can eventually become strong enough that the associated actions or behaviors can be accomplished with very little cognitive exertion. These strong connections can be drawn upon situationally when needed by the brain. The transfer of functions from the high-demanding prefrontal cortex to less-demanding areas of the brain frees up "processing power." Allowing the prefrontal cortex to focus on creative functions while other portions of the brain run "routine" and "well-learned" functions can result in increased creativity (Dubinsky, 2013; Ward, 2004). The mastery of vocabulary words as an essential element of learning a new language is an example of plasticity. As vocabulary words are learned and moved from the prefrontal cortex to other areas of the brain, the speaker of the newly acquired language can utilize increased creativity in conversation as more and more words, word-combinations, and sentence structures are now available. The synaptic-level connections 
between word and definition are strengthened with use until the new-language word can be used "without thinking" in the context of more elaborate communication. Conversely, several years of inactivity in language use weakens the synaptic connections, leading to higher processing required to recall and use previously learned vocabulary.

\section{Pedagogical Connections}

Research has demonstrated that teachers benefit from an understanding of neuroscience concepts through an increased ability to identify and teach these concepts to their students (Dubinsky, 2013). Additionally, an infusion of these concepts has the potential to transform teacher's understanding of student cognitive processes and consequently increase the ability to teach for student creativity. An innovative summer camp where teachers were introduced to neuroscience findings and encouraged to make classroom connections has already displayed great promise (Dubinsky, 2013). In addition to an understanding of neuroscience concepts, teachers can make a conscious effort to recognize and appreciate the great variety of creativity. While the pedagogical connections and unique implementations of these concepts are nearly endless, this paper aims to add a few discussion points for teachers as they initiate neuroscience concepts in their classrooms.

\subsection{Deliberate-Cognitive \& Spontaneous-Cognitive}

Most design challenges in the classroom are approached from a deliberate-cognitive viewpoint, i.e. students are taught to deliberately focus on the problem and come up with a creative solution. It is important to remember that the quantity of domain-specific informational items is key to deliberate-cognitive creativity. Without a large set of "tools" to select from individuals can relentlessly ponder the problem and never come up with a creative solution. Teachers can ensure students have sufficient "tools" (a.k.a. domain-specific informational items), from which to draw from prior to presenting them with a design problem. Separating the lesson outcomes into various informational items and ensuring each is addressed prior to undertaking any creative exercises can encourage deliberate-cognitive creativity in the classroom.

Spontaneous-cognitive creative moments are the "light-bulb" or "aha" occasions that most often occur during a state of mental relaxation while contemplating something else. In this scenario, previously unrelated information is processed in the prefrontal cortex and thus unforeseen connections may arise. Allowing students ample time to work on assignments or ponder over design challenges will increase the likelihood of this type of creativity occurring. Additionally, if teachers introduce problems and design challenges at the beginning of a unit, before presenting material related to the unit, it will increase the productive time in which spontaneous-cognitive creativity occurs. Likewise, increases in domain-specific knowledge will enhance the likelihood of this type of creativity to occur.

\subsection{Deliberate-Emotional \& Spontaneous-Emotional}

Students that do not excel at cognitive design challenges may be inclined towards emotionally creative activities. Emotionally creative expressions can occur deliberately or spontaneously. In deliberate-emotional activities individuals retrieve affective emotionally charged memories and infuse them into new situations. Allowing students to answer 
questions or solve design challenges through poems, music, dramatic representations, performances, or illustrations will foster an environment conducive to deliberate-emotional creativity. Teachers desiring to encourage emotional creativity can infuse all problems or challenges with an emotional consideration (i.e. Design a device that will allow users to relive their favorite childhood memories over and over).

Spontaneous-emotional creativity refers to moments of creativity which are unplanned and emotionally-charged. Encouraging students to maintain a class journal, blog, reflection-log, etc. is a good way to enhance spontaneous-emotional creativity. Students could be encouraged to write in their journal whenever they have creative ideas that are important to them and could be used to solve class challenges. Providing students with emotionally-charged and relevant questions can help guide and foster this creativity.

\subsection{Knowledge \& Creativity}

Due to the high level of domain-specific knowledge required for deliberate-cognitive and spontaneous-cognitive creativity, these categories of creativity are most frequently seen in adults or older adolescents. Conversely, deliberate-emotional and spontaneous-emotional creativity, which rely more on emotions than knowledge, can be exhibited at a much younger age. Teachers should approach their students with an understanding of the domain-specific knowledge possessed by each student. Students with greater domain-specific knowledge are more likely to produce creative ideas through deliberate-cognitive and spontaneous-cognitive processes.

\subsection{Plasticity}

An understanding of how synaptic connections can be strengthened or weakened can influence the pedagogy a teacher implements. Strong synaptic connections are formed through rehearsal, application, and self-evaluation of concepts (Dubinsky, 2013) and result in "processing" functions becoming "routine" functions. Functions are moved from the high-demanding prefrontal cortex to the less-demanding areas of the brain, thus, freeing up "processing-power" which can result in greater creative capabilities. Ensuring ample practice and mastery of key concepts may, in the long run, increase the creativity shown by students (i.e. introducing students to simple machines on day 1 and then reviewing simple machines on day 2-6). Teachers can also teach students about plasticity - this will facilitate student's understanding why so much time and effort are devoted to learning key concepts. In addition to helping students understand more about their brain, this practice has resulted in an increase of student motivation towards learning (Dubinsky, 2013).

\section{Conclusion}

For many years, a 19th century English physician named Edward Jenner worked to identify a cure for small pox. Despite great devotion of considerable time and effort, Jenner reached an impasse in his critical thinking. Jenner decided to try a completely different approach instead of focusing on people who had suffered small pox, he switched his attention to people who never contracted the illness. He ascertained that dairymaids rarely contracted the disease. He discovered that most dairymaids had had cow pox, a similar but usually nonfatal affliction. 
Cow pox had served to 'vaccinate' its victims against the more dangerous small pox. This led to Jenner's concept of 'vaccinating' people (VonOech, 2008).

Perhaps a successful strategy for mitigating creativity problems (Adobe, 2012; Kim, 2011) among students is to approach the issue from a different perspective. Teachers may be able to view their pedagogy through the lens of neuroscience with the application of Dietrich's creativity model. Additional research can be done relating to the infusion of neuroscience concepts in classrooms and the resulting creativity. Research on teachers and teaching methods as a result of the application of neuroscience understanding should also be conducted. Different models of creativity can be explored and findings should be compared with Dietrich's model. These findings as well as current research can substantially shape the way teachers perceive learning and teach for creativity.

\section{References}

Adobe. (2012). State of Create global benchmark study, Nasdaq: ADBE.

Christiaans, H., \& Venselaar, K. (2005). Creativity in design engineering and the role of knowledge: Modeling the expert. International Journal of Technology and Design Education, 15(3), 217-236. http://dx.doi.org/10.1007/s10798-004-1904-4

Clement, N. D., \& Lovat, T. (2012). Neuroscience and education: Issues and challenges for curriculum. Curriculum Inquiry, http://dx.doi.org/10.1111/j.1467-873X.2012.00602.x

Cowan, N (2001). The magical number 4 in short-term memory: A reconsideration of mental storage capacity. Behavioral and Brain Sciences, 24, 87-114. http://dx.doi.org/10.1017/S0140525X01003922

Dietrich, A. (2004). The cognitive neuroscience of creativity. Psychonomic Bulletin \& Review, 11(6), 1011-1026. http://dx.doi.org/10.3758/BF03196731

Dietrich, A. (2007). Who's afraid of a cognitive neuroscience of creativity? Science Direct, Methods, 42, 22-27. http://dx.doi.org/10.1016/j.ymeth.2006.12.009

Dubinsky, J. (2013). Infusing neuroscience into teacher professional development. Educational Researcher, 42(6), 317-329. http://dx.doi.org/10.3102/0013189X13499403

Fink, A. (2007). Creativity meets neuroscience: Experimental tasks for the neuroscientific study of creative thinking. Science Direct, Methods 42, 68-76. http://dx.doi.org/10.1016/j.ymeth.2006.12.001

Fuster, J. M. (1995). Temporal processing. Annals of the New York Academy of Sciences, 769, 173-182. http://dx.doi.org/10.1111/j.1749-6632.1995.tb38138.x

Fuster, J. M. (2000). Executive frontal functions. Experimental Brain Research, 133(1), 66-70. http://dx.doi.org/10.1007/s002210000401

Hamblyn, R. (2011). Newtonian apples: William Stukeley. The Art of Science. Pan Macmillan. 
IBM. (2010). IBM 2010 Global CEO study: creativity selected as most crucial factor for future success [Press Release]. Retrieved from http://www-03.ibm.com/press/us/en/pressrelease/31670.wss

International Technology Education Association (2007). Standards for Technological Literacy ( $3^{\text {rd }}$ ed.) Reston, Virginia 20191.

Kim, K. H. (2011). The creativity crisis: The decrease in creative thinking scores on the Torrance Tests of Creative Thinking. Creativity Research Journal, 23, 285-295. http://dx.doi.org/10.1080/10400419.2011.627805

Miller, G. A. (1956). The magical number seven, plus or minus two: Some limits on our capacity for processing information. Psychological Review, 63(2), 81-97. http://dx.doi.org/10.1037/h0043158

Norton, J. (2013). Chasing the light: Einstein's most famous thought experiment. Prepared for Thought Experiments in Philosophy, Science and the Arts, eds., James Robert Brown, Mélanie Frappier and Letitia Meynell, New York: Routledge, 2013.

Sarter, M., Givens, B., \& Bruno, J. P. (2001). The cognitive neuroscience of sustained attention: where top-down meets bottom-up. Brain Research Reviews, 35, 146-160. http://dx.doi.org/10.1016/S0165-0173(01)00044-3

Society for Neuroscience (2008). Neuroscience core concepts. The essential principles of neuroscience. Retrieved from http://www.brainfacts.org/About-Neuroscience/Core-Concepts

Srinivasan, N. (2007). Cognitive neuroscience of creativity: EEG based approaches. Science Direct, Methods, 42, 109-116. http://dx.doi.org/10.1016/j.ymeth.2006.12.008

VonOech, R. (2008). A whack on the side of the head. New York, NY: Business Plus, Hacette Book Group.

Ward, T. (2004). Cognition, creativity, and entrepreneurship. Journal of Business Venturing, 19, 173-188. http://dx.doi.org/10.1016/S0883-9026(03)00005-3

\section{Copyright Disclaimer}

Copyright reserved by the author(s).

This article is an open-access article distributed under the terms and conditions of the Creative Commons Attribution license (http://creativecommons.org/licenses/by/3.0/). 